\title{
The concept of methodology for communication and knowledge management in the organizations
}

\author{
RADOSŁAW ZAJĄC ${ }^{1}$ \\ Warsaw University of Technology, Faculty of Management
}

\begin{abstract}
The article analyses selected arguments for a universal methodology for managing communication and knowledge in organizations. On the basis of those conditions the principles of knowledge management are presented. Axioms underlying the logic model consistent with methodology is accompanied by a logic diagram of the other three components: the themes, processes and maintenance.

The postulated methodology of communication and knowledge management in organizations aims to provide a universal, cost-effective and efficient tool to support the daily operations of the company, change management and implementation of strategic objectives. At the same time implementation of the principles of this methodology may allow for an increase in commitment and enhanced performance of potential users of communication processes and knowledge management - by making users prosumers.
\end{abstract}

Paper type: conceptual article

Keywords: knowledge management, communication management, knowledge management methodology, Prince2, principles, prosumer

\section{Introduction}

Efficient management of the organization, effective current work, knowledge necessary to perform the tasks and innovations are based on a common denominator - communication. Communication understood as a flow of information, data and opinions - that make up knowledge and enable its use as well as build the value of

1 zajacra@poczta.onet.pl 
the organization. Observing the situation in the organization and analysis of the literature shows that there is a need to build methodology that will enable the comprehensive analysis of the processes of communication and knowledge management in organizations. The main task of this methodology is positioning of the selected area of communication and knowledge management among existing links in such a way as to sensitize business people and theorists on the actual complexity of communication and knowledge management. Furthermore, this methodology has the task of constructing open solutions for specific partial problems. ${ }^{2}$

The postulated communication and knowledge management methodology in the organization is to organize the relationship between the existing tools and concepts, created in response to specific problems relating to communication and knowledge management. As a result, existing solutions in this area are suboptimal, which in itself is not wrong, but the use of individual communication solutions and knowledge management in isolation from other scientific and practical achievements in this respect in certain specific situations can generate serious problems.

The aim of this article is to describe the design of original concept of communication and knowledge management methodology in an organization that supports the analysis, implementation and maintenance of knowledge management processes in an organization. This requires identifying critical subject areas that make up the knowledge management process, and which are necessary to ensure the expected efficiency and effectiveness of the methodology.

The concept of this methodology is based on the logic of the scheme of project management method Prince 2 - thus it consists of the four main components allowing for flexible adaptation of this tool to any organization.

\section{Communication and knowledge management in a company}

Taken considerations require clarification of the concept of communication. Adopted for the purpose of the proposed methodology approach similar to the description of communication by Ollivier (2010, p. 368), who believes that:

Communication can no longer be understood as sending the message that goes out from the sender to reach the recipient. One must understand that the circulation of messages on media determining their content is the subject of ongoing (re)interpretation on the part of users and active recipients-readers. Stereotypes that assume a purely telegraph communi-

2 The term open solution means in this context a solution that - as a module in the black-box analysis - is logical and consistent process-compatible with the other arrangements and aspects of knowledge. Black-box-analysis means analysis of complex systems-level modules and their relationships - without getting in all the details of the way of functioning of processes within the same module. 
cation, from old work on the transmission of information does not correspond to the current state of science.

From the practical point of view, one of the fundamental errors of communication (and knowledge management) is skipping its context. It is worth appealing to the example of the interpretation of a work of art, "the perception of something as art requires an element whose eye is unable to perceive the atmosphere of theory, knowledge of the history of art: the art world" (Danto, 1964, p. 581). Similarly, the perception of the message or item of knowledge is associated with the person of the recipient, user of this knowledge, which, through their knowledge and experience becomes, the co-creator.

Similar, but more formalized approach to communication, as opposed to the simplified approach by Shannon (2001), can be found in studies by Sundgren (1973) and Langefors (1980). Communication means for them providing information on an object belonging to a specific reality, its selected features, the values of these characteristics, and time - in which the object takes a certain value of the feature. This definition clearly reflects an object in the form of a theoretical object, first factor limiting the effectiveness of communication. In particular, the relationship between the object and the selected feature can mean the experience and existing knowledge on the part of recipient of a message - understood as a basic element of communication and knowledge management.

Referring to this definition one should also emphasize the issue of innovation - understood as the different context of existing processes or products. Increasingly, it is combined with knowledge management (discussion of selected topics is presented, for example, by Zuber [2012]).

The use of knowledge management as part of the development of innovation is not obvious and natural for the majority of the authors of studies in this area. Similarly practitioners involved in innovation neglect, often unconsciously, this aspect. And if they mention the knowledge they limit it only to the same innovations. But gradually emerge analysis on the relationship of these inextricably linked areas. For example, du Plessis (2007) emphasizes the role of knowledge management in building a competitive advantage through the use of knowledge distributed in the organization and creation of good practices of communication and exchange of knowledge. On the other hand, Shani draws attention to the next stage of knowledge management - showing the complexity of knowledge in the organization and accelerating the development through the mechanisms of knowledge management (Shani, Sena, \& Olin, 2003).

Quoted complementary positions show two basic aspects of knowledge management in the context of innovation:

- there is no culture of innovation in an organization that does not manage knowledge - then innovations are facade and are rather ephemeral and not the product of strategy and organizational culture, 
- sequence: knowledge management - innovation - using mechanisms for knowledge management in innovation allows the optimization of expenditures on innovation, maximizing the use of sources of innovation and commitment to innovation processes of more workers.

In turn, analysis of the organization functioning at the level of strategy, resorting to metaphors organization described by Morgan (1997), shows the universal goal of the organization, i.e. the survival on the market. If one adds to it the concept of value for stakeholders, a classic goal - to generate profit can be generalized to the basic one - creating value for the stakeholders (in particular for shareholders).

It is worth quoting an analysis of Beer, the outcome of which is specified as a great conspiracy of the training (Beer, Finnstrom, \& Schrader, 2016). Studies show that among the analysed training programs, only $10 \%$ was effective, because most of them neglect organizational changes across the company, focusing on the level of individual employees, or at most teams. The result - in the context of this article - is important mainly in two dimensions:

- direct application - training separated from the corporate changes, in particular the processes of communication and knowledge management, have limited effectiveness,

- generalizations confirming the role of knowledge management methodology - just change the organizational culture and the consistency of ecosystem development processes, employees and entire teams, will substantially improve the effectiveness of the various actions and partial processes.

\section{Problems in communication and knowledge management in the organization - critical analysis}

The author of the article, dealing with the issues of communication, training and knowledge management in one of the Polish insurance companies has identified a number of problems, which resulted in reducing both the efficiency of the functioning of both the same communication processes, training and knowledge management, as well as the consequences of these actions. In parallel with operational actions began analysing the real causes that affect this state of affairs. Author's observations on the evolution of the organization allow to determine the critical factors that may cause the decreasing effectiveness of existing models of communication in the organization, including:

- progress in management processes resulting in faster and faster changes in processes and products, 
- multiplicity of roles played by employees in life, in particular the role of a customer of other companies - and participant of social networking mechanism in the virtual and real-time communication.

Tools used to support communication and knowledge are many, thus the company can enjoy partial solutions, allowing to solve specific problems only in limited functionality span. Thus the tool, which is a strategy or plan for project communication often affects only communication in the project and its business environment - while logic components of this tool can be successfully used in other areas of communication. In turn, the knowledge base is too often seen only as a file repository. Meanwhile, the knowledge base interpreted as a set of processes to ensure the level of knowledge in the organization has completely different assumptions and effectiveness. As a result, creating a plan of action and solving emerging problems in the organization, specialist-practitioner once again could use the technique, which are used or to find own solution, often without sufficient knowledge about possible solutions described in the literature. Part of more informed and experienced communication professionals in organizations refer to industry magazines or tools popular in a given period. However, too often attached to these tools exceeds the limits of rationalism. It should be strongly emphasized that the above statements are not to criticize those involved in communication but a statement of fact. The problem at the business and the theoretical level is not lack, but an excess of solutions for communication and knowledge management in the organization. Each of these tools is to remove the problems, yet in fact generates new - which are often not described in theoretical models or guidelines implementation. Entrepreneurship, in its classic approach assumes the primacy of the operation and effectiveness of the analysis. Hence, often in the action plan does not have time to refer to the theory and in-depth analysis. It puts the efficiency of time and action. Here lies business justification for the creation of a universal methodology of managing communication and knowledge in the organization, which will enable the preservation of time efficiency taking into account the efficiency of communication and knowledge management processes in the organization.

Another factor impeding the optimization of activities within the framework of communication and knowledge management is settling on an annual, quarterly and monthly basis. Therefore, specialists and managers often focus on sub-optimal solutions that give the "best" solution "locally" - according to the measure of the time and area in the organization. In other words, in many cases, in an organization it is easier and safer to accomplish a task or change in one of the departments and show quick success than spend time and energy to build broader coalitions and sharing success through the implementation of fundamental transformation. Especially that the issue of communication and knowledge management is not always a clear priority for management. 
Communication and knowledge management is therefore not an end in itself - it is to bring change processes, change in employee behaviour, enable the management of an organization and increase its value (understood not only in financial terms) (see Goldhaber, 1993; Pathirage, Amaratunga, \& Haigh 2004). Hence, in addition to the standard view, one should look for inspiration and solutions to problems of communication and knowledge management in the model of Kirkpatrick (Kirkpatrick \& Kirkpatrick, 2006) and Bloom's taxonomy (Shelley, 2015).

Organizations and researchers form the descriptions of good practices or patterns of action on communication and knowledge management, for example Alavi (Alavi \& Leidner, 1999), Schreiber (2000) and Rubenstein-Montano with the team (2001). Knowledge management is moreover tied directly to the quality as in Bugdol and Jedynak (2015).

Elements of knowledge management also appear as part of the Code of ITIL (Taylor, Lacy, \& MacFarlane, 2007, p. 145): "The intention of the use of knowledge management is to ensure that the right information is delivered to the right person or the right place at the right time - to enable conscious decisions. The purpose of knowledge management is to enable organizations to improve the quality of management decision-making by ensuring the availability of reliable and secure information as well as data in the whole cycle of IT provision (Information Technology)."

The theoretical foundation of knowledge management methodology was described, among others by Sure (Sure, Staab, \& Studer, 2004) and Chalmeta (Chalmeta \& Grangel, 2008), however, these works present the theoretical approach to be implemented, translated into practical objects and terminology. In Poland, the demand for the construction of knowledge management methodology was formulated in 2006 by Żmigrodzki (2006): “(...) this is the moment when the field of knowledge matures and evolves from a dimension of art to crafts. The next stage is associated with a further increase in interest in the field of knowledge. But then one approaches the achievements already critical, and the expectations are more reasonable. In this phase, the discipline of knowledge - if it is positively verified - begins to spread. To be able to spread its assertions, theories, models, approaches, applications, etc. it should be formalized, unified and standardized. One of the tools that provide for the maturation of knowledge management is methodology." According to Żmigrodzki (2006) methodology of knowledge management should include specific areas (Table 1).

This inventory of the cognitive field, as it was described by Żmigrodzki, contains brief entries on the relevant aspects identified in the analysis of literature and implementation of elements of knowledge management in practice. However, the practice shows that this model is not intuitive in the details, it lacks the essential aspects - e.g. the dimension of applications. While definitely a positive conclusion is that the results quoted are in part coincident with the above idea. 
Table 1 The scheme of knowledge management methodology by Żmigrodzki

\begin{tabular}{|l|l|}
\hline \multicolumn{1}{|c|}{ Main components } & \multicolumn{1}{|c|}{ Particular/detailed elements } \\
\hline Assumptions & - process approach \\
& - subjugation of knowledge management to business processes \\
\hline Key areas & - innovations \\
& - knowledge transfer \\
& - maintaining knowledge management \\
& - didactics \\
& - life cycle of a member of an organisation \\
& - organisation in knowledge management \\
& - measurement and reporting \\
& - assessment of intellectual capital \\
& - implementation of knowledge management \\
& - particular methodologies \\
\hline Procedures & $\begin{array}{l}\text { Procedures realizing the targets of knowledge management initiatives related } \\
\text { to the structure of PMI methodology description presented in PMBOK Guide, } \\
\text { divided into several groups including: } \\
- \text { implementing } \\
- \text { executive } \\
- \text { control }\end{array}$ \\
\hline \multirow{2}{*}{ Techniques and tools } & Techniques and tools supporting knowledge management procedures \\
\hline
\end{tabular}

* Żmigrodzki points about 200 tools for knowledge management in literature on the subject.

Source: based on Żmigrodzki, 2006.

\section{Overview of logical communication and knowledge management methodology in the organization}

For a closer concept of communication and knowledge management in the organization methodology one should refer to the example of the evolution of management tools. If one looks at the development of concepts for process analysis and efficiency analysis, it turns out that evolution led from the class account of activity cost (ABC - Activity Based Cost) or Target Costing (TC) (Szychta, 2004), until the Balanced Scorecard (BSC) (Kaplan \& Norton, 1995). Each of the previous methods gives a suboptimal solution by modelling the specific aspect of business activity. While the balanced scorecard provides the tools to describe and manage the four strategic perspectives that allow to describe the whole spectrum of the organization.

By analogy to the above sub-relations tools to more advanced solutions, the idea of using Prince2 (Office of Government Commerce, 2009) originated to build a comparable concept of tools to support the implementation and management of communication and knowledge in the organization. The Prince 2 is a project management method functioning in the so-called customer-supplier environment. Its overarching goal is to ensure the continuity of the business case of the project and 
focus on the products - which, in particular means to meet the special, appropriately described acceptance criteria. As a result - as opposed to generating methodologies, agile or balanced scorecard - allows to build scalable structures and tools that are focused on specific objectives described by the products and the business levers that can be achieved by providing these products.

Furthermore, the use of advantages of this approach are:

- checked for completeness logical base model of reality - if over the years thousands of projects were carried out using Prince2, this model is logically consistent and covers all areas of activity,

- facilitating familiarizing oneself with the new methodology for people familiar with Prince2,

- at least consistency with Prince2 - to facilitate the implementation of the methodology of knowledge management projects with other basic products.

Prince 2 methodology has not previously been considered in the context of communications management and knowledge due to its versatility, providing primarily order the design and implementation of the goals of the organization that uses the products of the project. In particular, the Prince 2 does not address the issues of people management tools or specialized issues (for example in the area of knowledge management). Therefore, the proposed methodology of knowledge management is not only the result of changes in terminology, or fitting Prince 2 to a specific project, but the idea, based on the widely known and used approach.

Based on the experience gained from the implementation of knowledge bases and elements of knowledge management, as well as Prince 2 as a model of reference it was formulated an outline of a proprietary model of knowledge management methodology in four areas: the principles, themes, processes, and maintenance.

The basis of the whole methodology model is the Principles fulfilment of which determines compliance with the methodology of communication and knowledge management. ${ }^{3}$ Themes are the topics the focus of those implementing or maintaining a business management system communication and knowledge management must remain, indicating the tasks and important aspects of the life cycle of the business system for communication and knowledge management in organisations. Processes are tools to control the business system of knowledge management and recognition of dynamic flows in the organization. While Maintaining emphasizes the importance of post-implementation measures - both as a final implementation process, and the general tasks of current operations. These four elements of the methodology are similar to the structure of Prince $2 .{ }^{4}$

3 This is a similar solution to Prince2. If the project meets all the principles of Prince2, it is considered to be carried out in accordance with this method.

${ }^{4}$ The Prince 2 method basic elements are: principles, themes, processes and the project environment. 


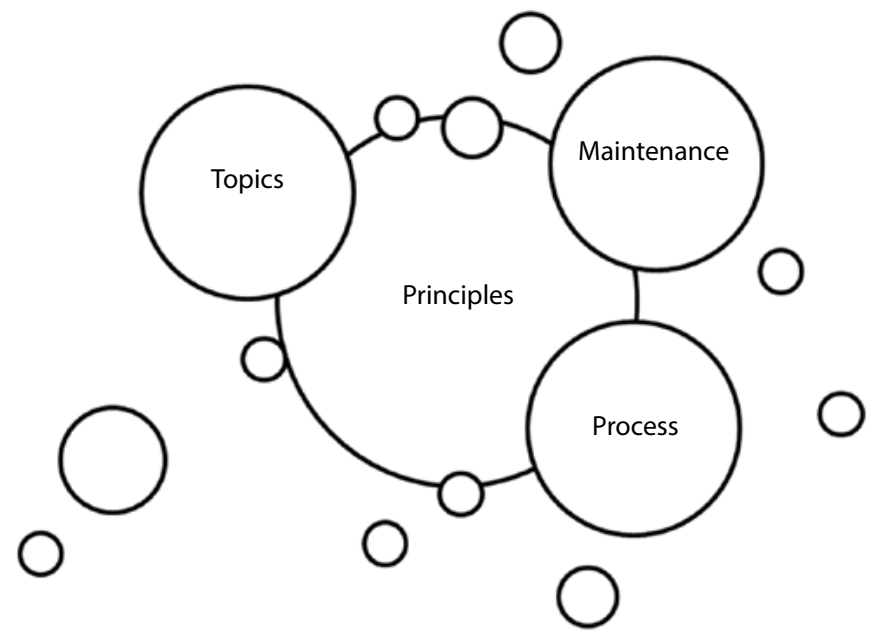

Figure 1. The scheme of components of communication and knowledge management methodology in the organization.

The article discussed in more detail only the Principles, that is axioms, the fulfilment of which is equivalent to implementing the methodology. Other components were sketched in their development, description and analysis of interdependencies will be the subject of separate studies.

Snowden has formulated seven principles (Dave Snowden's 7 Principles of Knowledge Management, 2009), but from the point of view of the proposed practical approach, they are too specific and are not completely independent of one another (i.e. there is excessive redundancy range). Hence the concept of the proposed methodology contains a different range (Table 2).

\section{Conclusions}

In business practice, communication and transfer of knowledge are not always treated as an integral part of management processes - as evidenced by observation of the actual processes and literature (Goldhaber, 1993). For example, it is quite common to send information or a decision on commencement of their term or only the day before that date. As part of the change management communication plans are build up, but they assume only the distribution of messages. In contrast, processing knowledge and management of objections and questions usually is no longer taken into account. This is evidenced, for example, significantly reducing the time to formulate questions or obtaining feedback from all users affected by the change. 


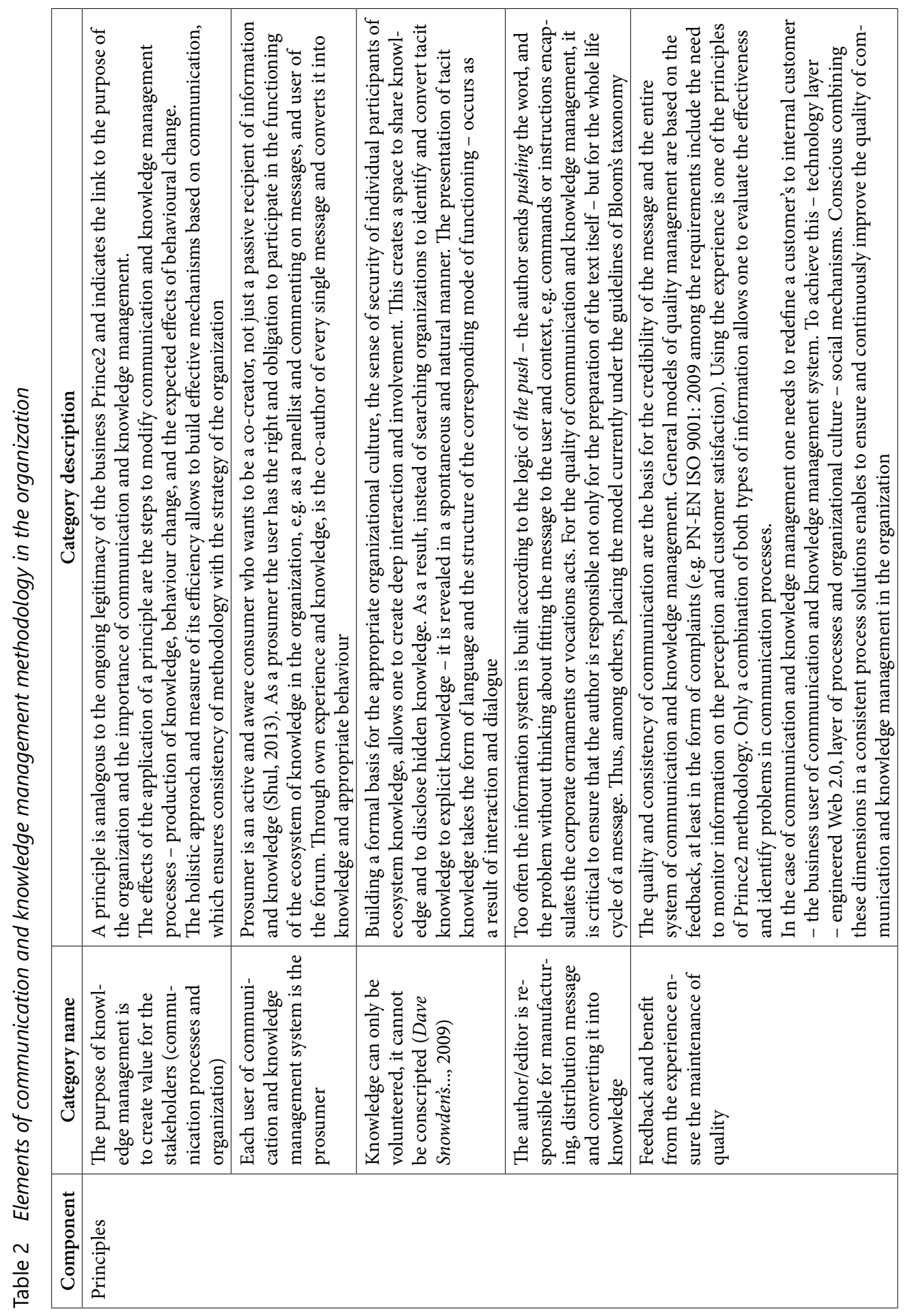




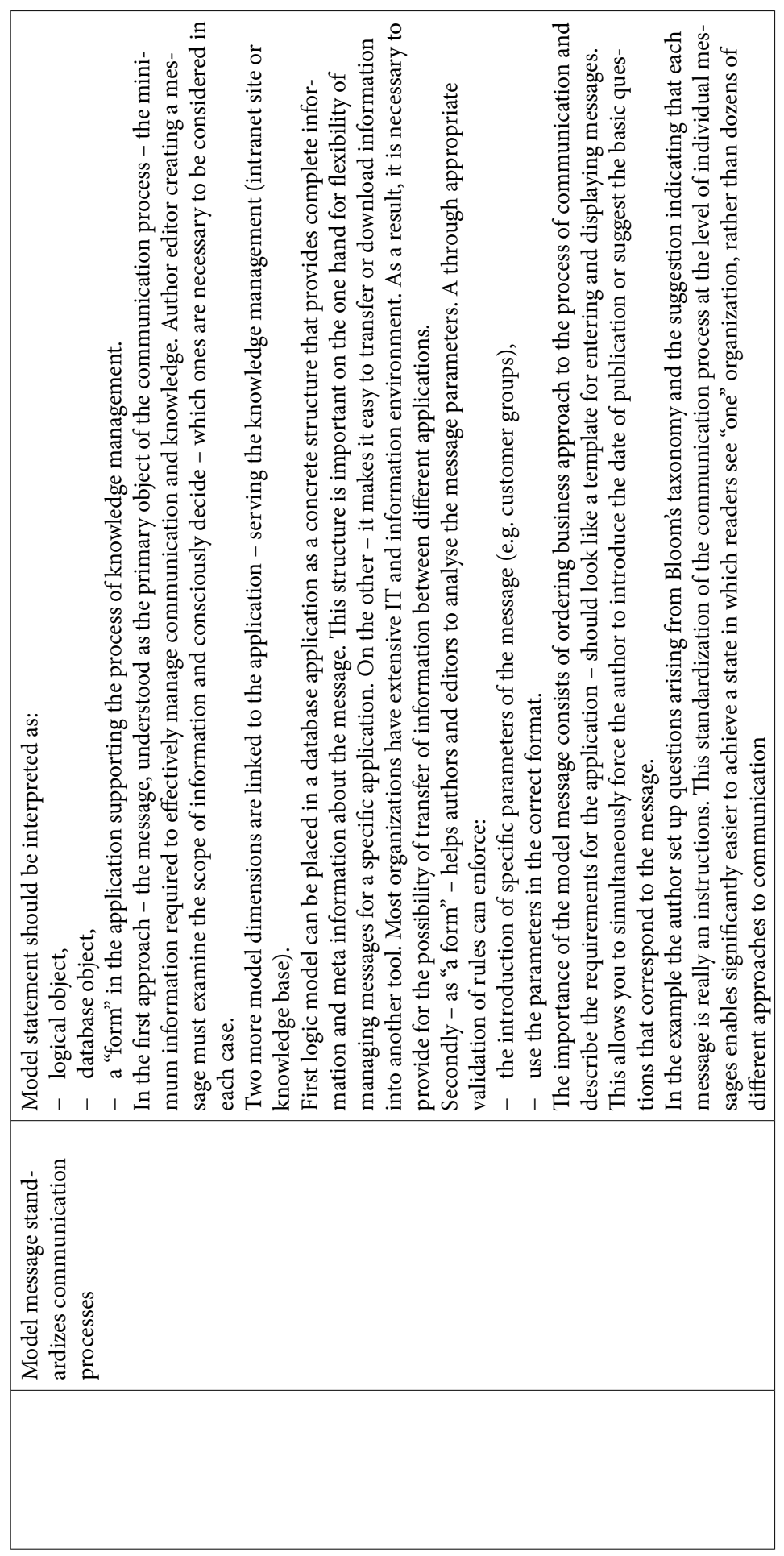

The concept of methodology for communication and knowledge management... 


\begin{tabular}{|c|c|c|c|c|c|c|c|c|}
\hline & 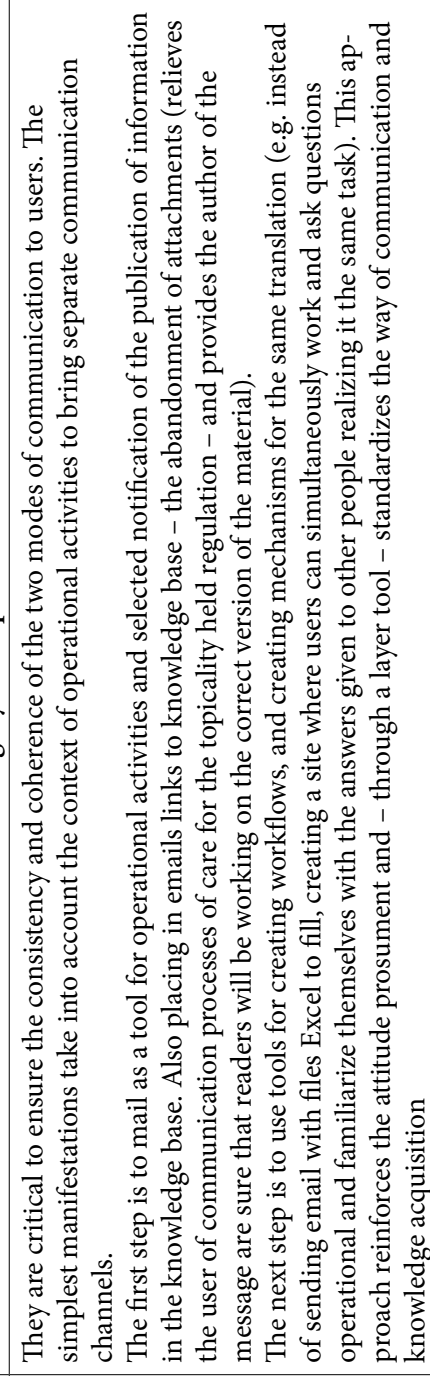 & 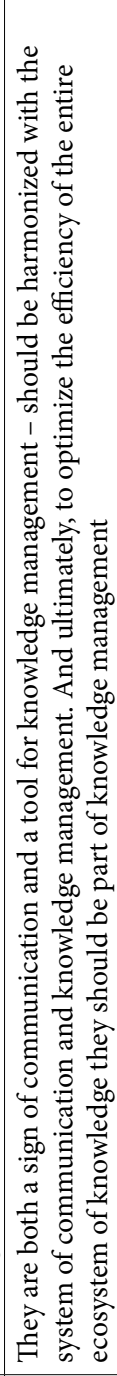 & 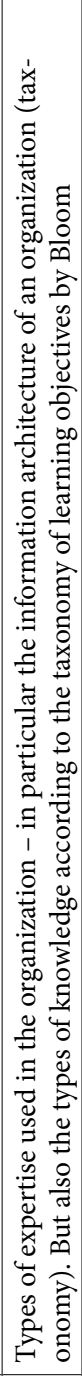 & 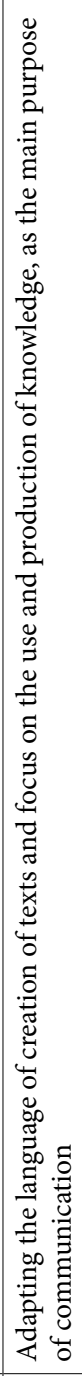 & 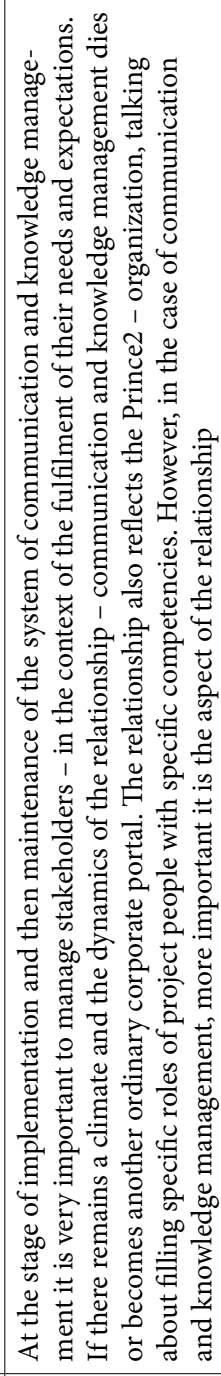 & 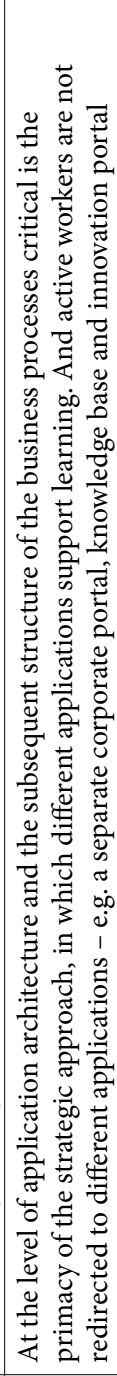 & 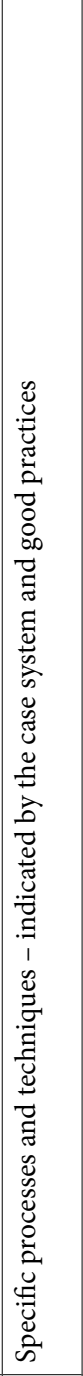 & 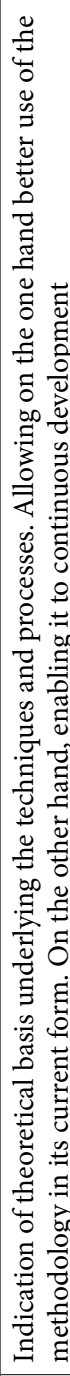 \\
\hline 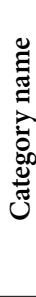 & 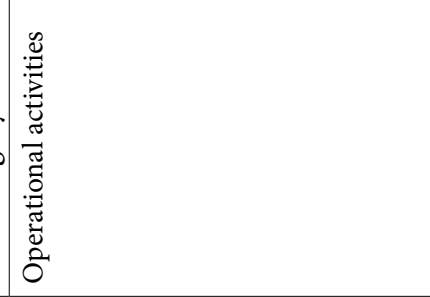 & 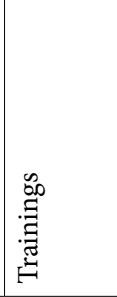 & 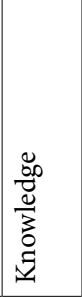 & 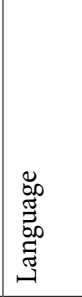 & 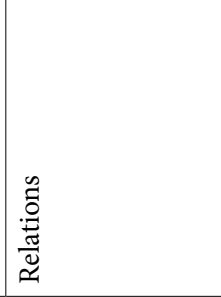 & 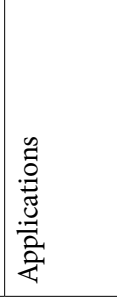 & 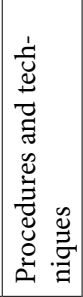 & 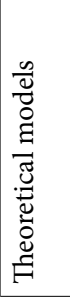 \\
\hline 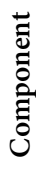 & 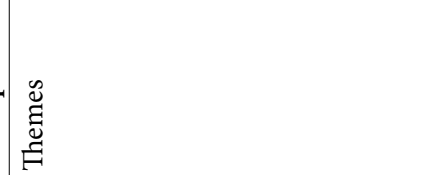 & & & & & & & \\
\hline
\end{tabular}




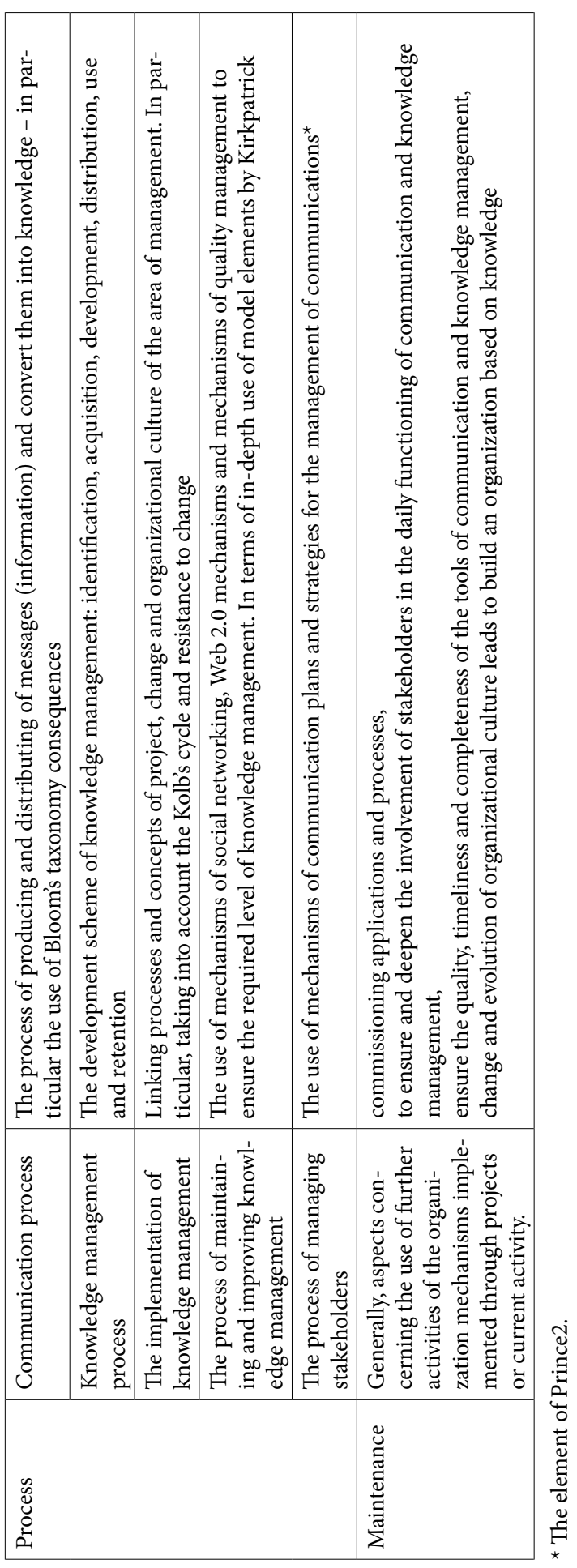


As a result of this separation of functions and activities in parallel are: management per se, communication and change management. While in many cases the empowerment of recipients of information, radically changes the way the changes go. First of all, by limiting the duration and strength stage of denial.

The aim of the postulated methodology is the integration of the selected achievements of science and workflows in one model, which allows for efficient and cost-effective implementation of elements of the whole communication and knowledge management system in the organization. In particular, this means the implementation stage, allowing you to add or modify the following products in a way not denying the existing achievements - the logic of open solutions. On the other hand, the methodology through its structure of four components is to enable asking the right questions, identifying the specific characteristics of the organization - as well as to make it easier to find answers through the suggested minimum range of processes and reference calling selected methods and techniques of communication and knowledge management.

Ensuring compliance with the methodology of communication and knowledge management in the organization is due to meet the Principles. Therefore, if an organization is interested in systemic approach to the management of this area of activity, should ensure the implementation of these Principles in the current business and project activity. According to the consequences of Gödel theorem (Mostowski, 1948) axiom system is not complete, however, for the construction of a universal methodology for managing communication and knowledge its extension should not require extension by more than 2-3 axioms. Other issues requiring detailed provisions should be moved to the level of guidelines and procedures to ensure readability model methodology.

Analysis by Themes enables the analyses of all the most important issues, which taking into account affects the efficiency of the implementation and quality of maintenance systems and processes of communication and knowledge management in an organization. In other words, Themes is understood as the sum of thematic areas ordering issues taken in the literature - recognized in this way, to provide the user of communication and knowledge management methodology in the organization of the possibility of a comprehensive look at the issues from the area. This eliminates the need to build specific models, starting with the details, but one can make sure that all aspects of communication and knowledge management have been addressed in the analysis frame, and detailed solutions are consistent with a holistic approach. In particular, the existing approaches to the methodology of knowledge management focus on the implementation of the methodology or its maintenance, while only approach in the long term - with particular emphasis on freezing changes - ensures the success of such a venture.

If one refers to the reasons of choosing topic: the rate of change of the business environment, the multiplicity of roles of a user of communication and knowledge management processes within and outside the organization, the multiplicity 
of tools and partial solutions - methodology provides a model analysis of the situation and combining existing and possible to implement tools and processes into one coherent system of communication and knowledge management in the organization. From a certain point of view, there is therefore nothing new. Yet its value lies in its versatility and the fact that existing tools and models can be seen as parts of a larger whole.

\section{References}

Alavi, M., \& Leidner, D.E. (1999). Knowledge management systems: Issues, challenges, and benefits. Communications of the AIS, 1(2), 1-36.

Beer, M., Finnstrom, M., \& Schrader, D. (2016). The great training robbery. Harvard Business School Research Paper Series, 16-121.

Bugdol, M., \& Jedynak, P. (2015). Quality in the selected management concepts. Jagiellonian Journal of Management, 1(2), 91-103.

Chalmeta, R., \& Grangel, R. (2008). Methodology for the implementation of knowledge management systems. Journal of the American Society for Information Science and Technology, 59(5), 742-755.

Danto, A.C. (1964). The Artworld. Journal of Philosophy, 61(19), 571-584.

Dave Snowden's 7 Principles of Knowledge Management (2009), retrieved from: http://www.gurteen.com/gurteen/gurteen.nsf/id/km-seven-principles [accessed: 16.09.2016].

du Plessis, M. (2007). The role of knowledge management in innovation. Journal of Knowledge Management, 11(4), 20-29.

Goldhaber, G.M. (1993). Organizational Communication. Madison: Brown \& Benchmark.

Kaplan, R.S., \& Norton, D.P. (1995). Putting the balanced scorecard to work. Performance Measurement, Management, and Appraisal Sourcebook, 66, 17511.

Kirkpatrick, D.L., \& Kirkpatrick, J.D. (2006). Evaluating Training Programs: The Four Levels. San Francisco, CA: Berrett-Koehler.

Langefors, B. (1980). Infological models and information user views. Information Systems, $5(1), 17-32$.

Morgan, G. (1997). Obrazy organizacji. Warszawa: Wydawnictwo Naukowe PWN.

Mostowski, A. (1948). Logika matematyczna. Warszawa-Wrocław: Instytut Matematyczny Polskiej Akademii Nauk.

Office of Government Commerce (2009). Managing successful projects with PRINCE2. The Stationery Office.

Ollivier, B. (2010). Nauki o komunikacji. Warszawa: Oficyna Naukowa.

Pathirage, C.P., Amaratunga, R.D.G., \& Haigh, R.P. (2004). Knowledge Management and Organisational Performance: A Literature Review. Research Institute for Built and Human Environment, University of Salford, Salford M7 1NU, retrieved from: http://usir.salford. ac.uk/9960/1/knowledge_management.pdf [accessed: 16.09.2016].

Rubenstein-Montano, B., Liebowitz, J., Buchwalter, J., McCaw, D., Newman, B., Rebeck, K., \& Team, T.K.M.M. (2001). A systems thinking framework for knowledge management. Decision Support Systems, 31(1), 5-16.

Schreiber, G. (2000). Knowledge Engineering and Management: The CommonKADS Methodology. Massachusetts: MIT Press. 
Shani, A.B., Sena, J.A., \& Olin, T. (2003). Knowledge management and new product development: A study of two companies. European Journal of Innovation Management, 6(3), 137149.

Shannon, C.E. (2001). A mathematical theory of communication. ACM SIGMOBILE Mobile Computing and Communications Review, 5(1), 3-55.

Shelley, A. (2015). Active Learning Innovations in Knowledge Management Education Generate Higher Quality Learning Outcomes, retrieved from: http://ssrn.com/abstract=2578654 or http://dx.doi.org/10.2139/ssrn.2578654 [accessed: 16.09.2016].

Sundgren, B. (1973). An Infological Approach to Data Bases. Stockholm: Skriftserie Statistika Centralbyran.

Sure, Y., Staab, S., \& Studer, R. (2004). On-to-knowledge methodology (OTKM). In Handbook on Ontologies. Berlin-Heidelberg: Springer, pp. 117-132.

Szul, E. (2013). Prosumpcja jako aktywność współczesnych konsumentów - uwarunkowania i przejawy. Nierówności Społeczne a Wzrost Gospodarczy, (31), 347-358.

Szychta, A. (2004). Rachunek kosztów działań i system kosztów docelowych jako instrumenty strategicznej rachunkowości zarządczej w warunkach globalizacji. Zeszyty Teoretyczne Rachunkowości, 18(74), 133-157.

Taylor, S., Lacy, S., \& MacFarlane, I. (2007). ITIL: Service Transition. Published by TSO (The Stationery Office).

Zuber, R. (2012). Innovation and Knowledge Management. Select Theoretical and Practical Issues. Warszawa: Difin.

Żmigrodzki, M. (2006). Metodyka zarządzania wiedzą. E-mentor,(1/13), 53-56, retrieved from: http://www.e-mentor.edu.pl/artykul/index/numer/13/id/247 [accessed: 16.09.2016].

\section{Note about the Author}

RADOSŁAW ZAJĄC - graduated from the Jagiellonian University (the Faculty of Mathematics). He also completed MBA and postgraduate studies from quality management. For 13 years he has worked as a lecturer at the Jagiellonian University and for an insurance company. His scientific work focuses on communication and knowledge management as well as project management and forecasting as a support for decision making. 